\title{
The new curriculum for family medicine at the University of Split, School of Medicine
}

\author{
Ivančica Pavličević \\ Department of Family Medicine \\ School of Medicine, University of Split \\ Split, Croatia
Corresponding author Ivančica Pavličević
Vukovarska 127
21000 Split
Croatia
ipavlice@mefst.hr
Tel.: + 38521475204
Fax: + 38521557820

Received: 9 January 2012

Accepted: 7 February 2012

Copyright (C) 2012 by

Academy of Sciences and Arts

of Bosnia and Herzegovina.

E-mail for permission to publish:

amabih@anubih.ba

\begin{abstract}
According to the new curriculum at the University of Split School of Medicine for the 2010/2011 academic year, the Department of Family Medicine based its teaching on its own expert and research work. The adequacy of the communication with the patient, his or her family and the social environment, as well as the concept of evidence-based medicine (EBM) have been defined as the foundation of expert and research work in family medicine. In accordance with this strategy, the members of the Department are involved in conducting journal clubs, Cochrane systematic reviews, research into the health of families where the father is absent working abroad (there are many such families with emigrant fathers in the region), and some are working on developing student letters to patients as an instrument for encouraging communication and empathy. The proportion of theoretical classes was reduced to provide more time for practice-based classes for students. The Work Diary was also introduced, as well as the student letter to the patient, practice of clinical skills and objective, structured, clinical examination (OSCE). The assessment of students is performed in four parts: the grade given by the student's practice supervisor, the grade for student letters to patients, the OSCE exam grade and the written exam grade. Students achieved, on average, very high grades. The Department is also involved in the course on clinical and social skills to first and second year students, taking on the task of introducing students to patients and their surroundings.
\end{abstract}

Key words: Family medicine, Classes, Students, Supervisors.

\section{Introduction}

Since 1974, School of Medicine at the University of Split (Split, Croatia), has been a branch of University of Zagreb School of Medicine (Zagreb, Croatia); in 1997 it became an independent school of the University of Split (1). It admits 75 students of medicine, 30 of dental medicine, and, since 2011, 25 students in an English language program. Jointly with the School of Chem- istry and Technology it also admits 25 students in the pharmacy program (2). It has around 100 full or part time teachers, who published 169 research articles in most prestigious international peer-reviewed journals in 2010 (http://neuron.mefst.hr/docs/ znanost/ured\%20za\%20znanost/Znanstvena\%20produkcija_graf_2000-2010.pdf).

School's Department of Family Medicine encompasses around 50 family medicine 
physicians who work in the city of Split, in Split surroundings and on Adriatic islands in the Split-Dalmatian County. Two problems have traditionally burdened the Department: the lack of systematic research in the field and the fact that the organization of Croatian health care system does not allow permanent engagement of family physicians as teachers. They cannot be formally employed even a small part of time, so their engagement in teaching process is paid per hour with a symbolic sum of money. This further diminishes their motivation for research, and often also for teaching.

According to the new curriculum of the Faculty of Medicine, adopted in February 2010, and started with the 2010/2011 academic year in October 2010, classes and examinations are standardized according to Bologna standards, ie, after the Provisions of Directive 2005/36/EC of the European Parliament and the European Council on recognition of professional qualifications from 7 September 2005. The program was drafted using the recommendations of Mission of experts for assessment of the situation in five regulated professions in the health sector in the Republic of Croatia conducted from 7 to 10 July 2008 for the new study program in Medicine, and with the provisions of the Regulated Professions and Recognition of Foreign Professional Qualifications Act passed by the Croatian Parliament in 2009 (Official Gazette no. 124/09). The program was amended according to the European Commission reviews received by the School together with the letter from Minister of Health and Social care of the Republic of Croatia from 24 January 2011 (class: 910-08/06-01/3, reg. no. 534-07-2-2/3-11-16) (2).

Special emphasis is given to students' clinical skills through an increase of the time they spend in a direct clinical work with patients $(1,2)$, and $60-70 \%$, of the final grade is earned during classes/semester and $30-40 \%$ during the exam itself. In this way, students are encouraged to give their best during classes. By completing each stage, the student collects points and takes the exam, when all of the points are tallied and the final grade determined (Figure 1).

Department of Family Medicine saw the curriculum reform as a great chance to reform, modernize and improve its organization and work, which received rather enthusiastic encouragement and support by the School's management. The physicians in the field (Split-Dalmatia County) were interviewed on their wish to contribute to students' family medicine clinical practice and

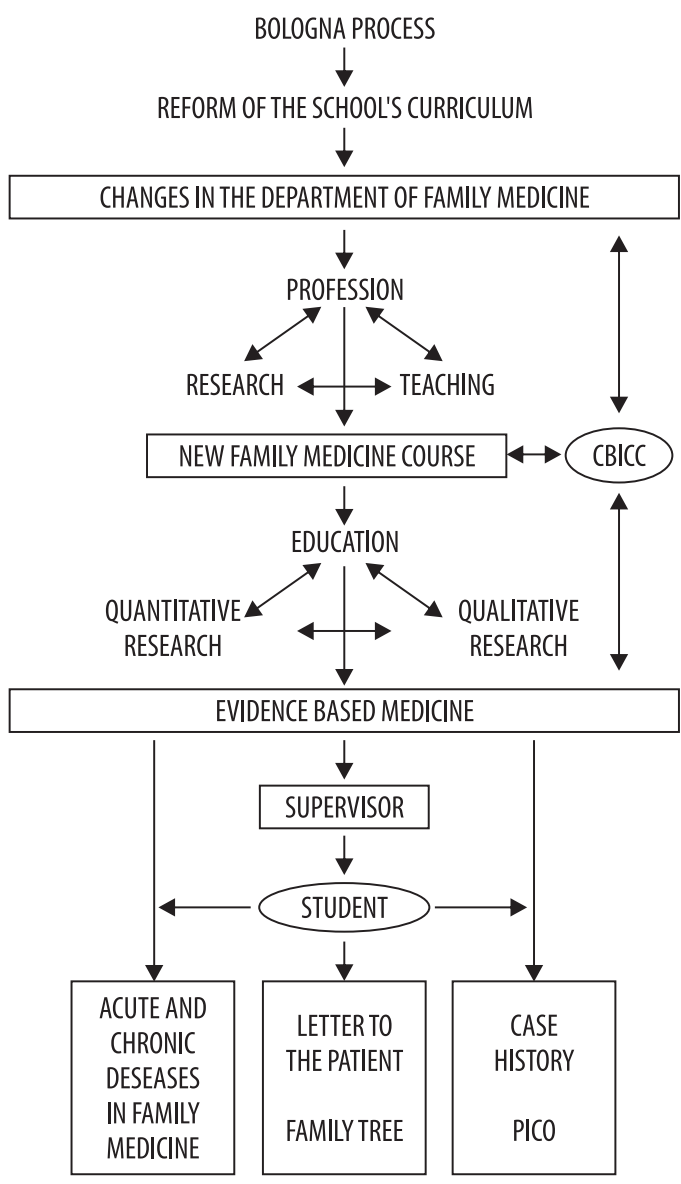

Figure 1 Development of the curriculum for family medicine at the Medical School in Split in 2010. Derived from the work and research of members of the Department, and founded on Bologna principles. CIBCC - Croatian Branch of Italian Cochrane Centre. 
those who responded positively were adopted as members of the Department. Communication and the meetings of the members of the Department were intensified, all members interested to become engaged in research (and take the track to achieve the $\mathrm{PhD}$ degree, which is in Croatia a prerequisite for professorship) were offered research themes and supervisors. Formal teaching was shortened and field work extended, and curriculum reformed in a number of its aspects (Table 1). This article summarizes those changes, which, together with our encouraging first results, warrant our belief that the new curriculum is worth describing, especially with respect to hard time that education in family medicine has passed in Croatia practically from its very beginnings.

\section{Expertise and research as a foundation and strategy for teaching}

Strategically speaking, our new curriculum integrates research and teaching, so that each affects the other and they follow the newest expert trends in family medicine. Two major educational aims were to improve student-patient communication and introduce evidence-based medicine (EBM) concept not only in the curriculum, but also in our family medicine practice. The insistence on student-patient communication we based on the introduction of student's letter to the patient as an instrument of teaching (exercise) and examination and, after the encouragement from the School's management, engagement of our teachers in the new course

Table 1. Basics of family medicine course content at the School of Medicine in Split

Competencies acquired

Distinguishing the particularities of health issues in ambulatory care. Ability of making clinical decisions. Recognition of concrete relationships patient-family-family physician. Clinical skills performed on the level of family medicine physician. Basic skills of acquiring evidence-based medicine information. Home treatment and monitoring of patients, prescribing medications, keeping records, cooperation with consultants, team work and community work, legislation and funding.

Contents

Characteristics of family medicine practice, family physician's tasks and scope of work, organization, financing and operation of the family medicine in Europe. Characteristics of health problems in the family medicine. Medical records. Cooperation with consultants, referral procedures for specialist examinations. Specific characteristics of the clinical procedures for family physicians. Administration of drugs in the family medicine practice. Communication in family medicine. Family and health. Home visits and home treatment, home care.

Particularities of care for patients in the family medicine. Evidence-based medicine. Levels of evidence in medicine. Legally prescribed and optimal space of family medicine clinics. Equipment in the family medicine. Medical bag. Organization of work, scheduling and receiving patients. Teamwork in the family medicine. Managing the family medicine clinic as a business unit. Administrative and legal obligations of family physicians. Assessment of working ability. Health educational and prevention activities as an integral part of the family physician's work. Prescribing medication. Home visits. Writing one letter per week to a selected patient.

Practical work in the School clinic, where students work under the supervision of a physician but as independently as possible*. Examination, diagnosis, differential diagnosis and tests are written informally in relation to the patient in a form of a seminar evaluated by the teachers.

Forms of teaching

Lectures (20 hours), seminars ( 60 hours), field work (with rotations of urban, rural and island offices 100 hours)

Method of knowledge assessment and examination

The final grade is obtained by scoring parts of the exam. Parts of the exam are: field work log, a letter to the patient about his illness and the written and practical part - objective structured clinical exam (OSCE).

*Planned when the School's office (under construction) is put in function. 
Clinical and Social Skills, posed in the first two study years of the School's curriculum. It turned out the School entrusted family medicine to be the first to introduce students to patients, as early as in the first study year.

Our plan to give significant emphasis to EBM was founded on the fact that School of Medicine in Split nourishes a rather active Croatian Branch of the Italian Cochrane Centre (3), which was successful in adequate education of several young and enthusiastic teachers. In this respect, we firstly formed a group of teachers, family physicians and interns who volunteered to master the basics of EBM. Together they have regular meetings, analyze articles related to the family medicine field of expertise and prepare clinical questions about problems from every- day practice and short evidence-based summaries. Some teachers in the Department perform research as part of the Cochrane collaboration, as well as for the World Health Organization. They are members of three international groups working on the following systematic reviews: "Celecoxibs in osteoarthritis treatment", "Probiotics in fibromyalgia treatment" and "Effects of different duration of postnatal hospital stay on the healthy survival of neonates during the first year of life born through uncomplicated vaginal delivery or Caesarean section".

Special attention is devoted to improve students' communication with the patient and his family, as well as with colleagues (Figure 2). Members of the Department have discussed this important issue on local

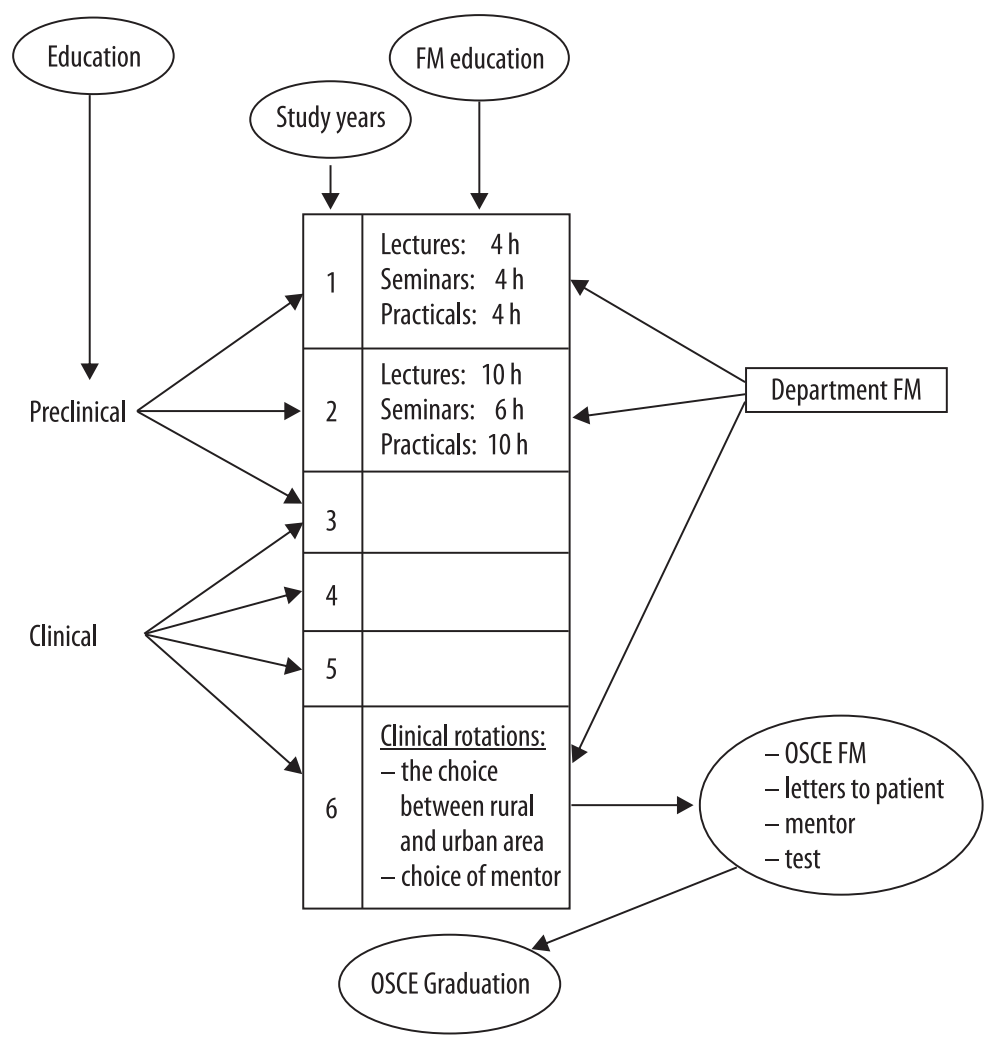

Figure 2 Position of education in family medicine within the curriculum of the Medical School in Split. In the first and second study years, family medicine helps introduce students to patients, medical settings and basics of communication with patients and colleagues. FM - family medicine; OSCE - objective structured clinical examination. 
TV and in the local newspapers. One group performs qualitative research about student letters to patients as an instrument for developing communication and empathy. Joint research is being planned with the Department of Family Medicine in Ljubljana, about health indicator differences between Slovenian and Croatian families.

A study about migrant families, "Influence of long-term absence of the family father due to economic emigration on physical, psychological and social health of family members at home country" is being conceived with a German partner. The study will be performed in Croatia and Germany, and the teachers from our Department will collaborate with German family physicians.

The members of the Department have been offered several doctoral theses: about the effects of fathers' absence due to work abroad on the health of family members, about the quality of health care in primary health care, and the specificities of health care on islands. There are three doctoral theses in progress, one of which is about to be completed. Recently we took part in writing and submitting a multilateral NATO project proposal.

Teaching in family medicine consists of lectures, seminars and family medicinebased practical classes. The Department's new policy is that the classes are not and should not be a repetition of previous study years and classes already taken. The students should have already absorbed the knowledge and skills; we believe that family medicine needs to teach students what "only we know and do", i.e. those skills and topics that they have not heard before, such as the organization of primary health care, multi-morbidity, preventive medicine, care of the elderly, managing patients with addictions, the care of terminal patients and home visits (4).

\section{Lectures}

The number of lectures has been significantly reduced compared to the previous academic years, in order to shorten the theoretical and lengthen the practical classes. We have also determined that, in teaching family medicine, "problem-based" seminars are much more useful to students than "ex cathedra" lectures. Lectures topics include family medicine as a medical discipline, organization of family medicine in Croatia and abroad, systems and documentation, importance of family medicine, family medicine in Europe, and male and female health (Table 1).

\section{Seminars}

We try to encourage students to take an active role in conducting the seminars by encouraging them to prepare in advance. We begin the seminar with a short introduction, upon which the discussion about practical cases is commenced, with the seminar leader acting as a moderator. Discussion on the presented patient is followed by looking for EBM answers on questions the discussion opened on patient's treatment and prognosis. Seminars cover the following topics: the febrile patient, communication skills, elderly health care in general medicine, protection of infants and small children, women's' health, managing addiction, treating cardiovascular risk factors, arterial hypertension, treatment of the most common gastrointestinal diseases, treatment of depressive patients, managing psychosomatic patients, protection of mental health, diabetes in general practice, urgent interventions in family medicine, illnesses of the thyroid gland, approach to patients with locomotor system problems, managing dizziness and headache, rheumatic diseases, pharmacotherapy, interactions, side effects, acute respiratory infections, chronic respiratory illnesses, and uropoietic system diseases (Table 2).

\section{Practicals}

Students undergo their practical classes in two groups, one in the city (in 13 practic- 
Table 2 Key features of the new courses at the School of Medicine in Split - Clinical and Social Skills I (first study year) and II (second study year)*

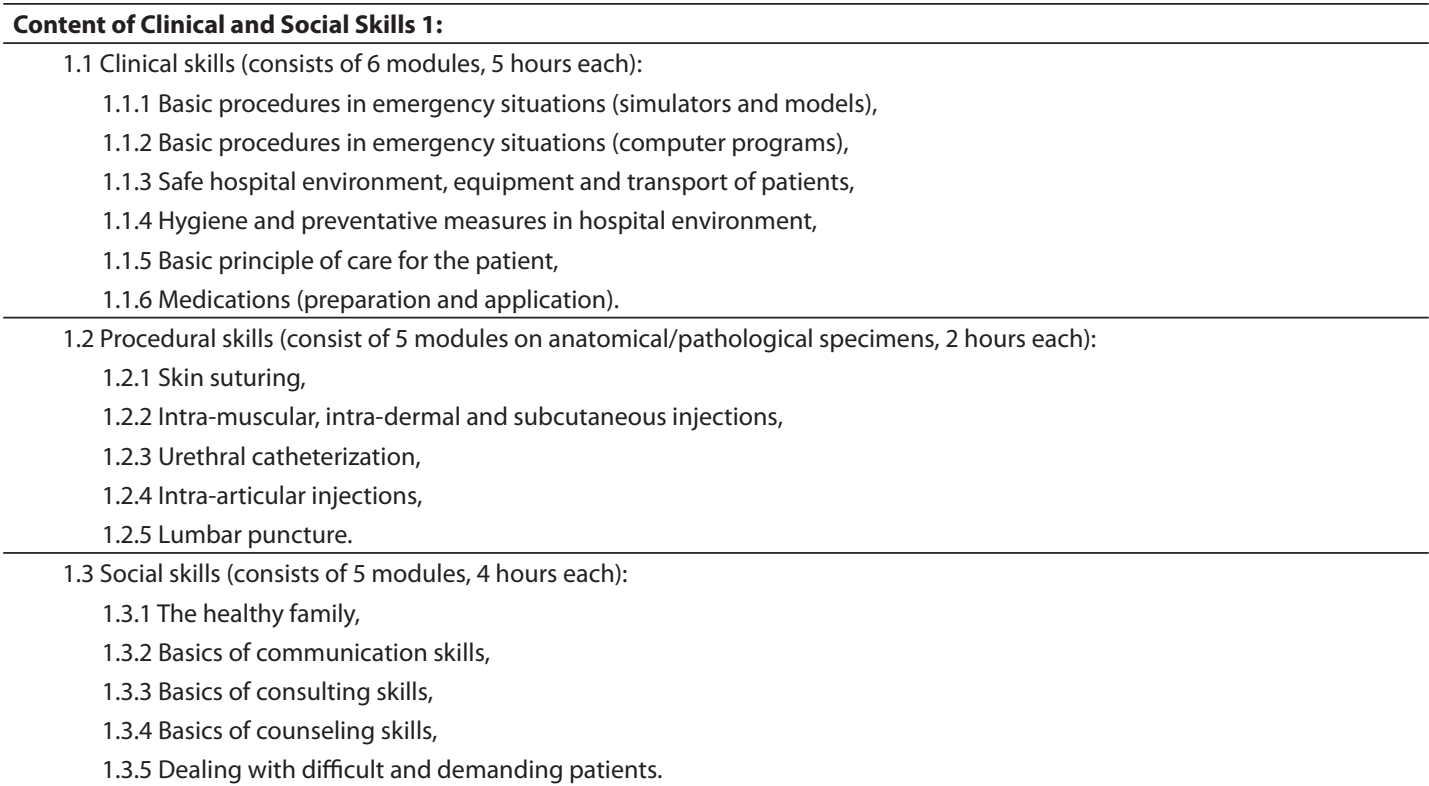

Examination related to the modules is done as objective structured clinical examination (OSCE) and contributes by $80 \%$ to the subject final grade.

1.4 Practical application and monitoring of clinical and social skills where every student spends 25 hours in the hospital/ primary care environment (equivalent of 4 working days). Each student has a set of questionnaires, relating to the performance of both clinical and social skills, observed amongst medical staff as well as the interaction between medical staff and patients. These questionnaires and short essays are assessed and contribute by $20 \%$ to the subject final grade.

\section{Content of Clinical and social skills 2 :}

1.1 Clinical skills (consists of 6 modules, 5 hours each):

1.1.1 Procedures in emergency situations: advanced module (simulators and models),

1.1.2 Procedures in emergency situations: advanced module (computer programs),

1.1.3 Medical documentation (organization, keeping, access),

1.1.4 Advanced clinical skills related to cardiovascular system,

1.1.5 Advanced clinical skills related to respiratory system,

1.1.6 Advanced clinical skills related to gastrointestinal system.

1.2. Procedural skills (consist of 5 modules on anatomical/pathological specimens, 2 hours each):

1.2.1 Arterial puncture and access,

1.2.2 Gastric intubation,

1.2.3 Abdominal puncture and drainage,

1.2.4 Thoracic puncture and drainage,

1.2.5 Airway establishment procedures.

1.3. Social skills (consists of 5 modules, 4 hours each):

1.3.1 Basics of team work management,

1.3.2 Basics of conflict resolution,

1.3.3 Basics of volunteering work,

1.3.4 Basics of special need care,

1.3.5 Basics of palliative care.

Examination related to the modules is done as OSCE and contributes by $80 \%$ to the subject final grade.

1.4 Practical application and monitoring of clinical and social skills where every student spends 25 hours in the social and special care institutions (e.g., developmental disability centers, institutions for aged). Each student has a set of questionnaires, relating to the performance of advanced communication and social skills, observed amongst staff as well as the interaction between staff and patients/clients. These questionnaires and short essays are assessed and contribute by $20 \%$ to the subject final grade.

*Both subjects include 85 hours of structured theoretical and practical teaching/instructions each, and they are divided into three parts: Clinical and procedural skills: 40 hours; Social skills: 20 hours; Practical application and monitoring of clinical and social skills: 25 hours. Developed by Professors Vladimir J. Šimunović, Ivica Grković and Matko Marušić. 


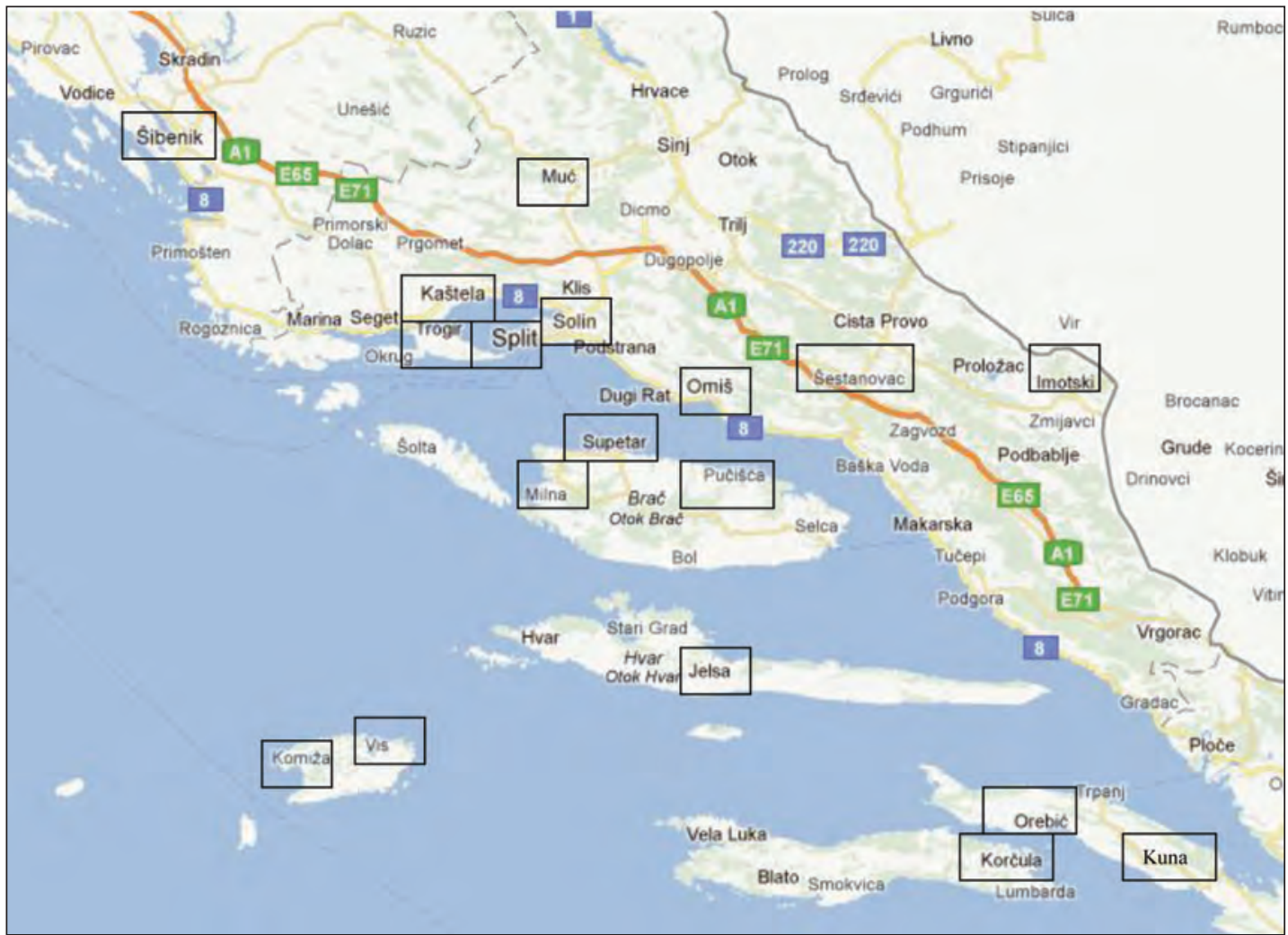

Figure 3 Family practices, in which the students perform their internships in the field, are located in Split, along the coast, in the hinterlands of Split (Dalmatinska Zagora), and the islands of Brač, Hvar, Vis and Korčula.

es in Split) or suburbs (5 practices around Split), and the other in rural locations including the Dalmatian islands (3 at Brač, 2 at Hvar, 3 at Vis and 1 at Korčula), the coast (Orebić and Kuna at the Pelješac peninsula), and in the Dalmatian Hinterland (Muć, Šestanovac, Imotski, Runovići) (Figure 3). It is these practical classes that students appreciate the most and consider the most valuable part of their education. In the new curriculum, we recognized the importance of students spending time in family medicine practices, and have accordingly adjusted content and duration of students' stay there. Along with daily work with patients, under supervisor supervision $(5,6)$, we have included students in research and taught them the advantages of using evidence-based medicine in family medicine $(7,8)$.

\section{Course examination}

The actual grading is divided into four parts: the grade from the practice supervisor, the grade for "student letters to patients", the objective standardized clinical examination (OSCE) grade, and the written exam grade - written test with 60 multiple-choice questions (Figure 2). Each part brings the student a certain number of points out of a maximum of 100 . The total number of points determined the final grade, as follows: 55-65 points $=$ sufficient, $66-75$ points $=$ fair, $76-85$ points $=$ very good, and 86 or more points = excellent. Exam points are scored for the following elements:

a. Grade from the practice supervisor, 0-20 points; 
b. Two "letters to examined patient", each of which brings 0 to 10 points, to a maximum of 20 ;

c. Objective standardized clinical exam (OSCE), 0-30 points;

d.Written test / exam, up to 30 points (60 questions).

Students showed great motivation and diligence during all parts of the assessment, and scored on average very high grades.

\section{Specifities of the new curriculum}

A daily record of work was introduced as a "Student diary", which allowed better tracking of student work during practical classes (Figure 4). It is the obligation of each student to record into the Diary everything that he or she did in the practice that day. During the first few days, the student works exclusively under supervisor supervision, while afterwards the independent work is encouraged. During one cycle of practical classes, the student completely takes all the skills necessary to conduct his or her own consultations. The diary is also helpful in tracking class attendance rates.

An obligation for students is also writing a letter to two of their patients about the patient's illness in a format that patients can understand, taking into account the patients' education, age, profession and social status, in order to practice communication skills. The student "sends" the letter to the patient whom he had examined and tries to explain everything about his condition in it.

Date:

STUDENT'S WORK DIARY

\begin{tabular}{|c|c|c|c|c|c|c|c|}
\hline TIME & $\begin{array}{l}\text { PATIENT'S } \\
\text { INITIALS }\end{array}$ & AGE & $\begin{array}{l}\text { PATIENT'S } \\
\text { REASON FOR } \\
\text { ATTENDANCE }\end{array}$ & $\begin{array}{l}\text { TOPICS } \\
\text { DISCUSSED WITH } \\
\text { MENTOR }\end{array}$ & \begin{tabular}{|l|} 
STUDENT'S OWN \\
CONSULTATIONS (UNDER \\
MENTORSUPERVISION)
\end{tabular} & $\begin{array}{l}\text { PARTICIPATION } \\
\text { IN OTHER } \\
\text { ACTIVITIES }\end{array}$ & $\begin{array}{l}\text { STUDENT'S } \\
\text { COMMENTS }\end{array}$ \\
\hline 08:00-8:30 & & & & & & & \\
\hline 08:30-9:00 & & & & & & & \\
\hline 09:00-09:30 & & & & & & & \\
\hline 09:30-10:00 & & & & & & & \\
\hline $10: 00-10: 30$ & & & & & & & \\
\hline $10: 30-11: 00$ & & & & & & & \\
\hline $11: 00-11: 30$ & & & & & & & \\
\hline $11: 30-12: 00$ & & & & & & & \\
\hline $12: 00-12: 30$ & & & & & & & \\
\hline $12: 30-13: 00$ & & & & & & & \\
\hline 13:00-13:30 & & & & & & & \\
\hline
\end{tabular}

Signature of student:

Signature of mentor:

Figure 4 The students enter physical examinations and procedures they have performed during their time in the family practice into the Work Diary. The diary serves as a reminder for exam preparation, as well as controlling the attendance rate. 
That way, the letters become a useful indicator of how the student is doing in the work with patients. We used two forms of such letters: "free-style" and "structured" (written in four paragraphs: history of illness, current symptoms and maladies, links between current state and the history of illness, and advice for the patient). In writing letters, the student needs to show adequacy and clarity in the description of the condition, knowledge, adequacy of the recommendation to the patient, empathy towards the patient and neatness and correct usage of language.

During classes, we teach students how to use evidence-based medicine in solving clinical problems and thus improve health care. We show them how to shape the patient's problem as a clinical question (PICO - patient; intervention; comparison; outcome), search the literature in for the best possible evidence and use it to solve the problem. This educational effort follows the paradigm that clinical practice based on evidence should be part of daily work for family medicine doctors in providing health care to the patient (10).

OSCE is a standard way of the assessment in family medicine $(10,11)$. The goal of OSCE exam is to objectively assess the competence of students in communication, clinical exam skills, skills in performing clinical procedures and clinical decisionmaking in a limited time-span $(12,13)$. Such an exam, as part of pre-graduate assessment, has never been implemented at our Medical School. Organizing an OSCE exam requires significant effort, material and a large number of organizers. At least 15-20 members of the Department took part in preparing and executing our OSCE.

During practical classes, we tried to have each student spend at least one day in touring the terrain with a district nurse, both in urban and rural environments. This way, the students had a much better look at the pa- tients' residence and ways of life, and noted the value of district nurse's work as a family medicine team member who cares about old, poorly mobile or disabled patients.

\section{Clinical and social skills 1 and 2}

The Department of family medicine will, as of the academic year 2011/2012, takes part in conducting classes in "Clinical and social skills 1 and 2". Within the scope of these classes, Departmental staff will get involved in teaching the basics of communication skills (how to establish communication, listening skills, empathy, types of communication, how to hold a therapeutic talk), while $2^{\text {nd }}$ year students will be taught advanced communication skills with patients and their families as part of "Clinical and social skills 2". There, the student implements the learned communication skills in reality, gets to know the complicated relations within a family, and determines the health problems of each particular family (see figure 2 and table 2). An early meeting of students with the patient, at the beginning of their studies, contributes to learning communication skills and a better understanding of the patient, and serves as an additional motivation for successful studying $(14,15)$.

\section{Student exchange}

The Department is also involved in student exchange with other medical schools. An exchange has been arranged with the Faculty of Medicine of Ljubljana (Slovenia), and Faculty of Medicine of Linkoping (Sweden). During the 2011 summer holidays, three students participated in the work of Ljubljana's Department of Family Medicine. They collected and sorted data for qualitative research about Slovenian families. One student is currently on an exchange visit to McGill University in Canada. 


\section{Discussion}

During the 2010/2011 academic year, teaching and assessment of family medicine was reorganized according to Bologna principles, and new contents were added (2). The value of practical work in supervisor practices is the basic code of every change. Similarly to the strategy of engaging students to contribute in some areas of our research, the professional, educational part of their work is based on a "partnership" concept, where the students are treated as young physicians. We try to encourage and empower them to work with the patients "instead of the doctor", and also "instead of the nurse" with, naturally, appropriate control and assistance. We believe that, besides introducing the first-year students to work with patients, the function of family medicine is also to complete students' competences of the independent work in health care. The practical work for students in family medicine course should include as little as possible presence of their teachers. Scientific work is encouraged at the Department. These activities were a part of the curriculum reform, which came just at the right time as part of the process of Croatia joining EU - we aimed at standardizing the curriculum to European criteria and thus achieving better results in teaching and increased students' satisfaction (16).

It is obvious that being a family physician who also participates in teaching bears enormous responsibility, and to participate in science as well is an even bigger respon-

\section{SUPERVISOR'S EVALUATION FORM}

Grade from the supervisor includes:

routine maintenance of the Work Diary (per day and per hour), punctuality and frequency of attendance, interest in working with patients and diligence,

relationship with patients (communication and empathy),

knowledge and application to learning.

The mark awarded can range from 0 to 4 , for a maximum of 20 points.

Student

Supervisor

Practice based teaching from to

\begin{tabular}{|l|l|}
\hline EVALUATION CRITERIA & POINTS \\
\hline Routine maintenance of Work Diary & \\
\hline Punctuality and frequency of attendance & \\
\hline Interest in working with patients and diligence & \\
\hline Relationship with patients (communication and empathy) & \\
\hline Knowledge and application to learning & \\
\hline Total points & \\
\hline
\end{tabular}

Figure 5 The supervisor rates students according to 5 criteria: routine maintenance of the Work Diary, punctuality and frequency of attendance, interest in working with patients, relationship with patients, knowledge and learning. The mark awarded can range from 1 to 4, for a maximum of 20 points. 
sibility, but also a challenge and pleasure. Our field of expertise, with its wide scope of work and wide range of data collection, has almost unlimited potential for research. By conducting research, we acquire new skills, broaden our knowledge and then transfer this knowledge to students. This way, we encourage students to join our research work, so that they can gain critical assessment skills early in their professional career. We developed a "synergetic action" model for the Department: expertise encourages science, science affects teaching, and teaching improves the whole field (Figure 1). This way, all members of the Department have found satisfaction and got involved, and have gained faith in their strengths and possibilities. The advantage of the Department of Family Medicine is a large variance in the terrains that our supervisors cover: village - city, islands - coast - hinterlands (Figure 3). This allows us to perform practical teaching in the environments in which young graduate doctors are actually going to work. The role of the supervisor is immeasurably valuable here $(17,18,19)$. The practice supervisors grade students according to the following criteria: routine maintenance of the Work Diary, attendance rate, interest in working with patients, relations with patients (communication and empathy), knowledge and learning (Figure 5).

By employing a larger number of family physicians to lead the practical classes, we are trying to achieve the "gold standard" of only one student per supervisor, which will significantly improve the quality of classes. Better education of current and newly involved supervisors has encouraged us to organize workshops for them. We are also planning to introduce teaching materials in digital format.

In short, the encouragement of research led to introducing a new kind of teaching at the Department. Research and expert work increase class quality, better teaching is a boon to further professional development, which opens up room for new research. We believe that a university teacher must also be a scientist in order to become a better teacher.

Acknowledgement: I am grateful to my colleagues family physicians who have so nicely cooperated and accepted the changes we introduced, to Professor Matko Marušić for his constant high spirits, encouragement and help, to Professors Igor Švab, Vladimir Šimunović and Ivica Grković for understanding and advice, and Professor Ana Marušić for unconditional support and critical reading of the manuscript.

Conflict of interest: The authors declare that they have no conflict of interest. This article was not sponsored by any external organisation.

\section{References}

1. Marušić M. History of School of Medicine in Split [in Croatian. In: Janković S, Boban M, editors. Sveučilište u Splitu, Medicinski fakultet, 1997.-2007. Split: Sveučilište u Splitu, Medicinski fakultet; 2007. p. 16-35.

2. Marušić $M$, editor. Curriculum of the integrated pregraduate and graduate program in medicine [in Croatian]. Split: School of Medicine, University of Split; 2011.

3. Puljak L, Rako D. Enhancing medical practice in Croatia through The Cochrane Collaboration. Biochemia Medica. 2009. 19(3):260-5.

4. Heyriman J, editor. The EURACT Educational Agenda. Leuven: European Academy of Teachers in General Practice, EURACT; 2005.

5. Sambunjak D, Straus SE, Marusic A. Menthoring in academic medicine: a systematic review. JAMA. 2006;296(9):1103-15.

6. Sambunjak D, Marusic A. Menthoring: What's in a name?. JAMA. 2009;302(23):2591-2.

7. Shapiro J, Coggan P, Rubel A, Morohasi D, Fitzpatrick C, Dangue F. The process of faculty-supervised student research in family medicine: motives and lessons. Fam Med. 1994;26(5):283-9.

8. Davidson RA, Duerson M, Romrell L, Pauly R, Watson RT. Evaluating evidence-based medicine skills during a performance-based examination. Acad Med. 2004;79(3):272-5.

9. Huić M. Evidence-based medicine. In: Marušić M, editor. Principles of evidence based medicine. Zagreb: Medicinska naklada; 2008. p. 219-33. 
10. Pavličević I, Šimunović V. Family medicine at the School of medicine in Split [in Croatian]. Liječ Nov. 2011;98:32.

11. Šimunović VJ, Hozo I, Rakić M, Jukić M, Tomić S, Kokić $S$, et al. New paradigm in training of undergraduate clinical skills: the NEPTUNE-CS project at the Split University School of Medicine. Croat Med J. 2010;51(5):373-80.

12. Tamblin R, Abrahamowicz R, Dauphinee D, Wenghofer E, Jacques A, Klass D, et al. Physician scores on a National Clinical Skills Examination as predictors of complaints to medical regulatory authorities. JAMA. 2007;298(9):993-1001.

13. Wallenstein J, Heron S, Santen S, Shayne P, Ander D. A core competency-based objective structured clinical examination (OSCE) can predict future resident performance. Acad Emerg Med. 2010;17(Suppl 2):S67-71.

14. Smithson S, Hart J, Wass V. Students' hopes and fears about early patient contact: Lessons to be learned about preparing and supporting students during the first year. Med Teach. 2010; 32(1):e24-e30.

15. Haffling AC, Håkansson A, Hagander B. Early patient contact in primary care: a new challenge. Med Educ. 2001;35(9):901-8.

16. Marušić M. Medical School in Split in the mandate period 2009-2011 [in Croatian]. Split: School of Medicine, University of Split; 2011.

17. Kadivar H. The Importance of mentorship for success in family medicine. Ann Fam Med. 2010;8(4):374-5.

18. Indyk D, Deen D, Fornari A, Santos MT, Lu WH, Rucker L. The influence of longitudinal mentoring on medical student selection of primary care residencies. BMC Med. Educ. 2011;11(1):27.

19. Chumley HS, Dobbie AE, Delzell JE. Case-based exercises fail to improve medical students' information management skills: a controlled trial. BMC Med Educ. 2006, 6:14doi:10.1186/14726920-6-14. 